\title{
The insulin-like growth factor-binding protein (IGFBP) family and its role in obesity and cancer
}

\section{Hatim Boughanem ${ }^{1}$, Amanda Cabrera Mulero ${ }^{2,3}$ and Manuel Macias Gonzalez $\mathbf{M}^{* 2,3}$}

${ }^{1}$ Biomedical Laboratory Research of Málaga (IBIMA). Faculty of science, University of Málaga, Málaga, Spain

${ }^{2}$ Unit of Clinical Management of Endocrinology and Nutrition, Málaga, Spain

${ }^{3}$ Biomedical Research Center in the Physiopathology Network of Obesity and Nutrition (CIBERObn), Madrid, Spain

Received: 眥 January 16, 2019; Published: 眥 January 25, 2019

*Corresponding author: Manuel Macias Gonzalez, Unit of Clinical Management of Endocrinology and Nutrition, Spain

Abstract

Insulin-like growth factors (IGFs) plays an interesting role as a growth factor. Its function is mainly modulated by family of IGF binding proteins (IGFBPs). There are six important members, which maintain a structural and functional similarity and perform different functions. Several studies have linked IGFBPs to obesity, insulin resistance, metabolic syndrome and cancer. In this article, we provide the most relevant and recent implication of IGFBPs member in obesity and cancer, and some approach of each member as a therapeutic target or biological biomarker.

Keywords: IGFBPs Family; Obesity; Cancer; IGFs

Abbreviations: IGFs: insulin-like growth factors; GH: growth hormone; IGFBP: IGF binding proteins; AKT: serine/threonine-protein kinase; IGF-1R: IGF-receptor type 1; RXR: retinoid X receptor; PPAR-囚: peroxisome proliferator-activated receptor type gamma; BMI: body mass index; T2D: type 2 diabetes; MAPK: Mitogen activated protein kinase; FOX: Forkhead box; mTOR: Mechanistic target of rapamycin kinase; GLUT4: Glucose transporter type 4. Type 1 diabetes: T1D

\section{Introduction}

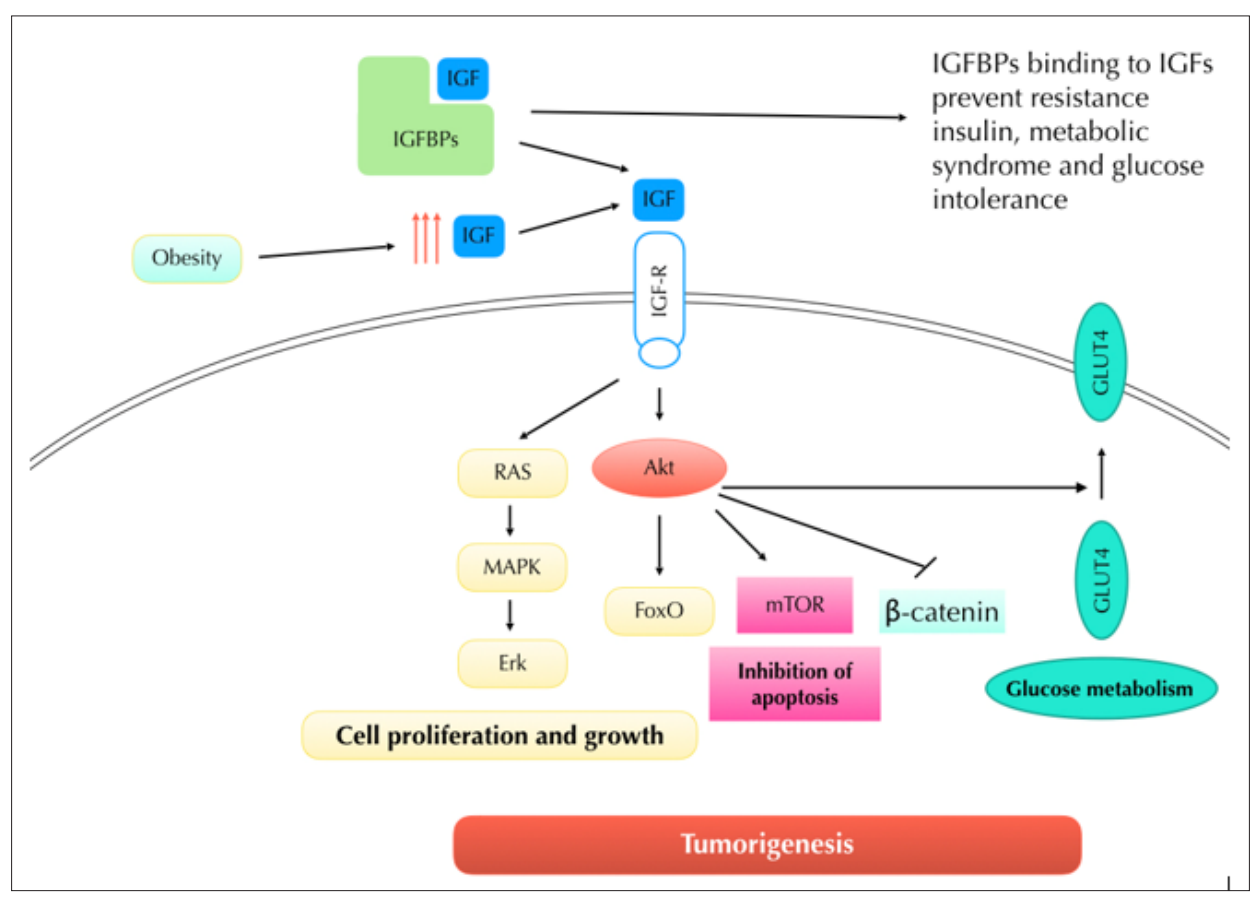

Figure 1: Schematic of IGF in obesity/cancer signaling and implication of IGFBP in their modulation. 
Insulin-like growth factors (IGFs) are a protein family that actively participate in mammalian development and growth [1]. These hormones function as the main mediator of somatic growth mediated by growth hormone (GH), as well as an important component of GH-independent anabolic responses [2,3]. The mechanism of action of IGF need a complex system to act, often, it is known as the IGF "axis" system. This system should include two IGFs type as IGF-type 1 (IGF-1) and IGF-type 2 (IGF-2), two cell-surface receptors such as IGF-receptor type 1 (IGF-1R) and IGF-receptor type 2 (IGF-2R), specific to each IGFs type with tyrosine kinase activity and a family of IGF binding proteins (IGFBPs) [4]. The response of the IGF/IGF-receptor binding results in kinase activation and initiation of intracellular signaling via the serine/threonine-protein kinase (AKT) pathway (Figure 1) [5]. Interestingly, the IGFBPs family modulate the signaling process since it regulates the biological actions of IGFs in two different ways, the IGF receptor-dependent model (IGFBPs can act as an inhibitor, preventing the IGF/IGF-receptor association and as an activator, facilitating binding with IGF receptors) and IGF receptor-independent model (increasing the half-lives of the IGFs or providing a means of functional and/or tissue specificity) [6].

There are a six well characterized high affinity mammalian IGFBPs genes, designated IGFBP-1 through -6, and another not well-defined low affinity IGFBPs family, since IGFBP-7 to -10. Together, they constitute the IGFBP superfamily [7]. The primary structures of high-affinity binding IGFBPs family contain three principal domains: The N-terminal domain, the mid-region and the C-terminal domain. The $\mathrm{N}$-terminal domain share approximately $58 \%$ of sequence between the six component of the high-affinity IGFBPs. This domain is characterized by containing 12 cysteine residues highly conserved. Within this domain, a local motif (GCGCCxxC) is also well conserved among the IGFBPs. However, the significance of this motif is as yet unknown [7-9]. The mid-region separates the $\mathrm{N}$ - from the $\mathrm{C}$-terminal domain. The sequence for this domain appears to be unique to the family members. Two principal post-transductional modifications are present into. There are glycosylation and phosphorylation. The ability to bind to IGFs with high affinity appears not be influenced by N- or O-glycosylation, although there may be effects on resistance to proteolysis.

The purpose of phosphorylation is yet unclear, but there is evidence that phosphorylation may affect to the affinity for IGFs [7-10]. Finally, the C-terminal domain is highly conserved. Six cysteines is found and are strictly conserved and involved in intradomain disulfide bond formation. Interestingly, the C-terminal domain sequences share high similarity with the thyroglobulin-type-I domain. Although its function is unknown, this domain is found in a number of proteins with varying physiological functions in different organisms $[7,11]$. The low-affinity IGFBP family share structurally only few characteristics in the N-terminal domain with the high affinity IGFBP family. The C-terminal domain shows a significative structural and functional differences, which suggests its role in the affinity to IGF. The C-terminus is also highly variable in the low affinity IGFBP family, which differs in the number of domains, structure, sequence and function [7].

\section{The Implication of the IGFBPs Family in Obesity and Cancer}

IGFBP-1: Insulin-like growth gactor binding protein type 1 (IGFBP-1), functions as an inhibitor of the cellular and fetal growth by sequestering IGFs in hypoxia condition [12]. It is also a negative regulator of the p53/BAK-dependent pathway of apoptosis [13]. Due to this functions, IGFBP-1 could play an important role in obesity and cancer. Several studies have been concluded that conditioned levels of IGFBP-1 affects by physiological variation of glucose and insulin, which glucose stimulates the secretion of IGFBP-1 while insulin suppresses IGFBP-1 secretion [14,15]. The implication for chronically low IGFBP-1 in obese and diabetes patients could increase IGF bioavailability, deteriorating metabolic functions and provide chronic mitogenic stimuli of relevance for neoplastic transformation in target cells and tissue. However, the involvement of IGFBP-1 in cancer is yet unclear and remain controversial. Some studies suggest that IGFBP-1 inhibits IGF-1 induced growth (Figure 1). But more studies are needed to clarify if this mechanism has significant effects on tumor growth [16].

IGFBP-2: Insulin-like growth factor binding protein type 2 (IGFBP-2) regulates several cellular processes such as proliferation, cell migration, and adhesion. Epidemiological studies indicate that IGFBP-2 is associated inversely with adiposity related insulin resistance, body mass index (BMI) and insulin sensitivity in the context of type 2 diabetes (T2D). In obesity, circulating levels of IGFBP-2 are suppressed, and low levels are associated with T2D and metabolic syndrome [17]. Recent studies have also demonstrated that the overexpression of IGFBP-2 inhibits both adipogenesis and lipogenesis in visceral, but not subcutaneous, adipocytes. The effect was observed in the presence and the absence of IGF-1, showing an independent inhibitory effect on adipogenesis. There indicate that IGFBP-2 could have a protective function in obesity and diabetes $[18,19]$. IGFBP-2 is one of the commonly expressed IGFBPs in a wide range of human cancers [20]. Increased serum IGFBP-2 levels are associated with multiple cancers as prostate, breast, ovarian and colorectal cancer [21]. Moreover, overexpression or addition of exogenous IGFBP-2 also induces proliferation, migration and invasion of these cells [22]. These results can purpose IGFBP-2 as a promising target to inhibit the metastasis and overcome the chemo-resistance and an independent indicator of malignancy.

IGFBP-3: The main function of insulin-like growth factor binding protein (IGFBP-3) is related to the bioavailability of IGF-1, binding to and sequestering IGF-1, and to exert IGF-1 independent effects. Therefore, IGFBP-3 modulates the principal biological actions of the IGFs [23]. Recent studies have been shown the role of IGFBP-3 in metabolic regulation in adipose tissue. IGFBP-3 overexpression in transgenic mice suggests that IGFBP-3 results in fasting hyperglycemia, glucose intolerance, and insulin resistance [24]. IGFBP-3 can act in an IGF-independent manner by translocating to the nucleus and bind to retinoid $\mathrm{X}$ receptor (RXR) and Peroxisome proliferator-activated receptor type gamma (PPAR- $囚$ ), inhibiting adipose differentiation [25]. This signaling could be also regulated by vitamin D system, showing a new alternative mechanism in insulin signaling associated with obesity [26]. IGFBP-3 is also implicat- 
ed in cancer. More specifically, IGFBP-3 is known as a pro-apoptotic molecule and growth inhibitory with a protective effect on large cancer type as prostate, colorectal, breast or lung cancer. However, this effect is controversial in different cancer type and further research is needed to clarify the role of IGFBP-3 in the pathogenesis of cancer [27].

IGFBP-4: The liver is the main source of circulating insulin-like growth factor binding proteins (IGFBP-4), that is involved in the systemic and local regulation of IGF activity [28]. The role if IGFBP-4 in adipose tissue is unclear, additional finding is required to clarify the direct effect of this protein to delay or attenuate adipose tissue dysfunction in humans and metabolic syndrome. More studies also show the conflictive association between IGFBP-4 BMI, glucose metabolism and insulin resistance [29]. Careful interpretation of data is necessary as such findings require support by more studies. IGFBP-4 acts by binding to IGF-I and IGF-II and modulating its biological effects [30]. There is interesting because it could be an important effect in cancer development, although additional studies are needed. The expression of IGFBP-4 have studied in large cancer type with controversial results. There is known that overexpression IGFBP-4 inhibits cellular growth IGF-induced and through a through a mechanism independent of IGFs in vitro and in vivo. Moreover, most cancers express IGFBP-4 at levels which correlate with their state of differentiation. Overexpression of IGFBP-4 in vivo has been reported to decrease the growth of prostate cancer. The effect of altered expression of IGFBP-4 in vivo in colon and other cancers needs to be explored as locally available IGFs appear to stimulate mitogenesis. Thus, the effects of IGFBP-4 on tumor growth are uncertain [31].

IGFBP-5: Insulin-like growth factor binding protein -5 (IGFBP-5) is the most conserved gene of the IGFBPs family in all vertebrates. It acts binding to IGFs, leading to altered cell proliferation, apoptosis, survival and cell migration. Only a few studies have been linked the effect IGFBP-5 with obesity. A study has examined the association of polymorphism on the IGFBP-5 gene with metabolic syndrome. This study has shown that these polymorphisms were strongly associated with serum adiponectin concentration in glucose intolerance patients. There also founded a positive correlation between IGFBP-5 and adiponectin gene expression in subcutaneous adipose tissue in metabolic syndrome patients [32]. However, more finding is needed to confirm the role of IGFBP-5 in glucose metabolism. IGFBP-5 participates in development of cancer in IGF-dependent and independent context. It has been discovered that IGFPB-5 is expressed in a multiple cancer type. However, further research into the role of the IGFBP-5 axis in tumor growth is required to resolve the functional implication in cell proliferation [33,34].

IGFBP-6: The principal function of insulin-like growth factor binding proteins -6 (IGFBP-6) is inhibiting IGF-II actions. More specifically, IGFBP-6 inhibits cell proliferation, differentiation and migration induced by IGF-II. In contrast, has few or no effect on IGF-I actions, due to its lower binding affinity [35]. A study has been demonstrated the relationships between IGFBP- 6 concentrations and Type 1 Diabetes (T1D) patients. The logistic regression data suggests that T1D patients with higher IGFBP- 6 are at an increased risk of developing complications of other organs. That is shown the important modulator role of IGF-II in [36]. The expression of IGFBP-6 is lower tumoral cells, suggesting an inhibitory effect. IGFBP-6 prefers binding to IGF-II over IGF-I. A principal role for IGFBP-6 is inhibition of their actions following a dependent model, but recent studies also shown that IGFBP-6 also could act on IGF-independent manner, by angiogenesis inhibition and tumoral cell migration [37]. Thus, can suggest a possible targeted-therapy against specific tumor that depend on IGF-II to growth.

\section{Conclusion}

The IGFBP family has a relevant role in the disorder associated with obesity such as glucose intolerance, metabolic syndrome or insulin resistance. But this implication needs to be approached with more studies, especially in family members from IGFBP-4 to IGFBP-6. The IGFBP family also have an interesting participation in cancer development. It participates on tumor growth, differentiation or cellular migration. This suggests that IGFBPs may be an interesting therapeutic target, which implies a reduction in the growth of IGF-dependent tumors.

\section{Acknowledgements}

\section{Funding}

This study was supported by "Centros de Investigación En Red" (CIBER, CB06/03/0018) of the "Instituto de Salud Carlos III" (ISCIII). Grant from ISCIII (PI18/01399) and co-financed by the European Regional Development Fund (FEDER). ACM was the recipient of an FPU grant from Education Ministry, Madrid, Spain (Ref: FPU16/02011); and MMG was the recipient of the Nicolas Monardes Program from the "Servicio Andaluz de Salud, Junta de Andalucía”, Spain (RC-0001-2018).

\section{Authors' Contributions}

The authors' responsibilities were as follows. HB, ACM and MMG contributed to the project conception and performed writing of the first draft of the manuscript, and primary responsibility for the final content of the manuscript. All authors were involved in the writing of the manuscript and approving the final version of this article.

\section{References}

1. RG Rosenfeld (2003) Insulin-like Growth Factors and the Basis of Growth. N Engl J Med 349(23): 2184-2186.

2. N Mauras, MW Haymond (2005) Are the metabolic effects of GH and IGF-I separable? Growth Hormone and IGF Research 15(1): 19-27.

3. RG Rosenfeld (2005) The molecular basis of idiopathic short stature. Growth Horm IGF Res, p. 3-5.

4. D Cannata, A Vijayakumar, Y Fierz, D LeRoith (2010) The GH/IGF-1 Axis in Growth and Development: New Insights Derived from Animal Models. Advances in Pediatrics 57(1): 331-351.

5. J Riedemann, VM Macaulay (2006) IGF1R signalling and its inhibition, in Endocrine-Related Cancer 13(1): 33-43.

6. SB Wheatcroft, MT Kearney (2009) IGF-dependent and IGF-independent actions of IGF-binding protein-1 and -2: implications for metabolic homeostasis. Trends in Endocrinology and Metabolism. 
7. V Hwa, Y Oh, RG Rosenfeld (1999) The insulin-like growth factor-binding protein (IGFBP) superfamily. Endocrine Reviews 20(6): 761-787.

8. T Sitar, GM Popowicz, I Siwanowicz, R Huber, TA Holak (2006) Structural basis for the inhibition of insulin-like growth factors by insulin-like growth factor-binding proteins. Proc Natl Acad Sci 103(35):1302813033.

9. CA Galea, Mobli M, McNeil KA, Mulhern TD, Wallace JC, et al. (2012) Insulin-like growth factor binding protein-2: NMR analysis and structural characterization of the N-terminal domain. Biochimie 94(3): 608-616.

10. Y Yamanaka, JL Fowlkes, EM Wilson, RG Rosenfeld, Y Oh (1999) Characterization of insulin-like growth factor binding protein-3 (IGFBP-3) binding to human breast cancer cells: kinetics of IGFBP-3 binding and identification of receptor binding domain on the IGFBP-3 molecule. Endocrinology 140(3): 1319-1328.

11. A Sala, Capaldi S, Campagnoli M, Faggion B, Labò S, et al. (2005) Structure and properties of the C-terminal domain of insulin-like growth factorbinding protein-1 isolated from human amniotic fluid. J Biol Chem 280(33):29812-29819

12. RM Popovici, M Lu, S Bhatia, GH Faessen, AJ Giaccia, et al. (2001) Hypoxia regulates insulin-like growth factor-binding protein 1 in human fetal hepatocytes in primary culture: Suggestive molecular mechanisms for in utero fetal growth restriction caused by uteroplacental insufficiency. J Clin Endocrinol 86(6): 2653-2659.

13. JI Leu, DL George (2007) Hepatic IGFBP1 is a prosurvival factor that binds to BAK, protects the liver from apoptosis, and antagonizes the proapoptotic actions of p53 at mitochondria. Genes Dev 21(23):3095109.

14. JM Holly, DB Dunger, JA Edge, CP Smith, T Chard, et al. (1990) Insulin-like growth factor binding protein-1 levels in diabetic adolescents and their relationship to metabolic control. Diabet Med 7(7): 618-623.

15. JU Weaver, Holly JM, Kopelman PG, Noonan K, Giadom CG, et al. (1990) Decreased sex hormone binding globulin (SHBG) and insulin-like growth factor binding protein (IGFBP-1) in extreme obesity. Clin Endocrinol 33(3):415-422.

16. A Hoeflich, VC Russo (2015) Physiology and pathophysiology of IGFBP-1 and IGFBP-2 - Consensus and dissent on metabolic control and malignant potential, Best Practice and Research: Clinical Endocrinology and Metabolism 29(5): 685-700.

17. AH Heald, K Kaushal, KW Siddals, AS Rudenski, SG Anderson, et al. (2006) Insulin-like growth factor binding protein-2 (IGFBP-2) is a marker for the metabolic syndrome. Exp Clin Endocrinol Diabetes 114(7): 371-376.

18. A Hoeflich, Wu M, Mohan S, Föll J, Wanke R, et al. (2009) Overexpression of insulin-like growth factor-binding protein-2 in transgenic mice reduces postnatal body weight gain. Endocrinology 140(12): 54885496.

19. SB Wheatcroft, Kearney MT, Shah AM, Ezzat VA, Miell JR, et al. (2007) IGF-binding protein-2 protects against the development of obesity and insulin resistance. Diabetes 56(2): 285-294.

20. A Hoeflich, Reisinger R, Lahm H, Kiess W, Blum WF, et al. (2001) Insulinlike growth factor-binding protein 2 in tumorigenesis: protector or promoter? Cancer Res 61(24): 8601-8610.

21. A Pickard, DJ McCance (2015) IGF-binding protein 2 - Oncogene or tumor suppressor?, Frontiers in Endocrinology 6: 25.
22. S Han, Z Li, LM Master, ZW Master, A Wu (2014) Exogenous IGFBP-2 promotes proliferation, invasion, and chemoresistance to temozolomide in glioma cells via the integrin $\beta 1$-ERK pathway. Br J Cancer 111(7): 1400-1409.

23. S Jogie Brahim, D Feldman, Y Oh (2009) Unraveling insulin-like growth factor binding protein-3 actions in human disease, Endocrine Reviews 30(5): 417-437.

24. HS Kim (2013) Role of insulin-like growth factor binding protein-3 in glucose and lipid metabolism. Ann Pediatr Endocrinol Metab 18(1): 9-12.

25. SS Chan, LJ Schedlich, SM Twigg, RC Baxter (2009) Inhibition of adipocyte differentiation by insulin-like growth factor-binding protein-3. Am J Physiol Endocrinol Metab 296(4): 654-663.

26. I Moreno Santos, D Castellano Castillo, MF Lara, JC Fernandez Garcia, FJ Tinahones, et al. (2017) IGFBP-3 Interacts with the Vitamin D Receptor in Insulin Signaling Associated with Obesity in Visceral Adipose Tissue. Int J Mol Sci 18(11): 465-467.

27. O Ali, P Cohen, KW Lee (2003) Epidemiology and Biology of Insulin-like Growth Factor Binding Protein-3 (IGFBP-3) as an Anti-cancer Molecule. Hormone and Metabolic Research 35(11-12):726-733.

28. MF Gude, J Frystyk, A Flyvbjerg, JM Bruun, B Richelsen, et al. (2001) The production and regulation of IGF and IGFBPs in human adipose tissue cultures, Growth Horm. IGF Res 22(6): 200-205.

29. R Hjortebjerg (2018) IGFBP-4 and PAPP-A in normal physiology and disease. Growth Horm IGF Res 41: 7-22.

30. Y Honda, EC Landale, DD Strong, DJ Baylink, S Mohan (1996) Recombinant synthesis of insulin-like growth factor-binding protein-4 (IGFBP-4): Development, validation, and application of a radioimmunoassay for IGFBP-4 in human serum and other biological fluids. J Clin Endocrinol Metab 81(4): 1389-1396.

31. R Durai, Davies M, Yang W, Yang SY, Seifalian A, et al. (2006) Biology of insulin-like growth factor binding protein- 4 and its role in cancer (review). Int J Oncol 28(6): 1317-1325.

32. P Kallio, Tolppanen AM, Kolehmainen M, Poutanen K, Lindström J, et al. (2009) Association of sequence variations in the gene encoding insulinlike growth factor binding protein 5 with adiponectin., Int. J. Obes. (Lond) 33(1): 80-88.

33. J Beattie, GJ Allan, JD Lochrie, DJ Flint (2006) Insulin-like growth factorbinding protein-5 (IGFBP-5): a critical member of the IGF axis. Biochem J 395(1): 1-19.

34.G Güllü, S Karabulut, M Akkiprik (2012) Functional roles and clinical values of insulin-like growth factor-binding protein-5 in different types of cancers. Chin J Cancer 31(6): 266-280.

35. LA Bach (2005) IGFBP-6 five years on; not so 'forgotten'? Growth Horm IGF Res 15(3): 185-192.

36. S Lu, Sharad Purohit, Ashok Sharma, Wenbo Zhi, Mingfang He, et al. (2012) Serum insulin-like growth factor binding protein 6 (IGFBP6) is increased in patients with type 1 diabetes and its complications. Int J Clin Exp Med 5(3): 229-237.

37. LA Bach, P Fu, Z Yang (2013) Insulin-like growth factor-binding protein-6 and cancer. Clin Sci 124(4): 215-229. 
ISSN: 2574-1241

DOI: $10.26717 / B J S T R .2019 .13 .002436$

Manuel Macias Gonzalez. Biomed J Sci \& Tech Res

(c) (i) This work is licensed under Creative

Submission Link: https://biomedres.us/submit-manuscript.php

$\begin{array}{ll}\text { BIOMEDICAL } & \text { Assets of Publishing with us } \\ \text { RESEARCHES } & \text { - Global archiving of articles } \\ & \text { - Immediate, unrestricted online access } \\ & \text { - Rigorous Peer Review Process } \\ \end{array}$

